\title{
Caffeine, Diabetes, Cognition, and Dementia
}

\author{
Geert Jan Biessels* \\ Department of Neurology, Rudolf Magnus Institute of Neuroscience, University Medical Center, Utrecht, The \\ Netherlands
}

\begin{abstract}
People with diabetes mellitus are at increased risk of cognitive dysfunction. This review explores the relation between caffeine intake, diabetes, cognition and dementia, focusing on type 2 diabetes (T2DM). Epidemiological studies on caffeine/coffee intake and T2DM risk are reviewed. Next, the impact of T2DM on cognition is addressed. Finally, the potential for caffeine to modulate the risk of cognitive decline in the context of diabetes is explored. The conclusion is that, although epidemiological studies indicate that coffee/caffeine consumption is associated with a decreased risk of T2DM and possibly also with a decreased dementia risk, we can at present not be certain that these associations are causal. For now, recommendations for coffee consumption in individuals with T2DM or pre-diabetic stages are therefore difficult to establish, but it should be acknowledged that caffeine does appear to have several properties that warrant further investigations in this field.
\end{abstract}

Keywords: Alzheimer's disease, caffeine, coffee, cognition, dementia, diabetes mellitus, epidemiology, insulin, stroke, vascular dementia

\section{INTRODUCTION}

People with diabetes mellitus are at increased risk of cognitive dysfunction. The nature and severity of diabetes-associated cognitive decrements varies with age and diabetes type [1]. On the occasion of the meeting "Caffeine and the Brain", which was held in Lisbon, June 2009, this review explores the relation between caffeine intake, diabetes, cognition and dementia. The focus will be on type 2 diabetes (T2DM), because both epidemiological studies on the relation between caffeine intake and incidence of diabetes, and studies on the relation between diabetes and incidence of dementia predominantly involve individuals with T2DM. First, epidemiological studies linking caffeine/coffee use to reduced T2DM risk will be reviewed. Next, the impact of T2DM on cognition will be addressed. Finally, the potential for caffeine to modulate the risk of cognitive decline in the context of diabetes will be explored.

\footnotetext{
* Correspondence to: Geert Jan Biessels, Department of Neurology, G03.228, University Medical Center, PO Box 85500, 3508 GA Utrecht, The Netherlands. Tel.: +31 88 7557975; Fax: +31 30 2542100; E-mail: g.j.biessels@umcutrecht.nl.
}

\section{CAFFEINE AND T2DM}

\section{A brief update on T2DM}

Insulin resistance is a key feature of T2DM [2]. In initial stages, insulin resistance is compensated by an increase in insulin secretion by the pancreas. Once this compensation fails, glucose levels start to rise. When glucose levels reach the thresholds defined in diagnostic criteria, currently $7.0 \mathrm{mmol} / \mathrm{l}$ for fasting plasma glucose and $11.1 \mathrm{mmol} / \mathrm{l}$ for a casual glucose sample [3], diabetes is diagnosed. Hence, the progression from normal glucose metabolism to T2DM is a gradual process that evolves over many years. Well before the onset of T2DM, insulin resistance is accompanied by other metabolic and vascular abnormalities (e.g. obesity, dyslipidemia, raised blood pressure, and prothrombotic and proinflammatory states) $[4,5]$. This cluster of risk factors is referred to as the metabolic syndrome [4] and predisposes to T2DM as well as to cardiovascular disease [4]. Indeed, there is a strong association between T2DM and atherosclerosis [6]. In addition T2DM is associated with so-called microvascular complications, 
but these mainly occur after the actual onset of hyperglycemia [7].

Treatment of patients with T2DM is directed at improvement of the vascular risk factor profile and lowering of glucose levels through reduction of insulin resistance (for example, with diet, exercise or drug therapy), or stimulation of endogenous insulin secretion [2]. Eventually, exogenous insulin can be needed.

Age is an important determinant of T2DM risk. The annual T2DM incidence increases from $<0.1 \%$ below the age of 30 to $1 \%$ around the age of 70 years (e.g. [8-10]). Currently, in Europe and the USA the prevalence of diabetes peaks around an age of 70 years, at 10 to $20 \%[11,12]$. Genetic factors also play a role: a positive family history confers a 2.4 fold increased risk for T2DM [2]. In the context of this review it is important to note that obesity, lifestyle, and overeating seem to be the triggering pathogenic factors [2], and that lifestyle and socioeconomic factors are held responsible for much of the worldwide increase in the incidence and prevalence of diabetes [13].

\section{Coffee and T2DM: epidemiological evidence}

In 2002, data from a large prospective populationbased cohort linked coffee consumption to reduced T2DM risk [14]. Individuals who reported to drink at least seven cups of coffee a day were 0.50 (95\% CI $0.35-0.72$ ) times as likely to develop T2DM as those who drank two cups or fewer. These risk estimates were adjusted for potential confounders, since coffee use was related to several other socioeconomic and lifestyle variables that affect T2DM risk, such as level of education, physical activity, and diet.

Since then, several studies confirmed these observations. In a meta-analysis of 9 cohort studies of coffee consumption and risk of T2DM, including data on close to 200.000 individuals, the relative risk of T2DM was 0.65 (95\% CI $0.54-0.78)$ for the highest category of coffee consumption ( 6 or 7 cups per day) and 0.72 (95\% CI 0.62-0.83) for the second highest (4-6 cups per day), compared with the lowest consumption category ( 0 or $\leqslant 2$ cups per day) [15]. A later study from the USA indicated that reduced T2DM risk was mainly attributable to the consumption of decaffeinated, rather than regular coffee [16], but this observation is at variance with those of European studies that mainly concerned consumption of regular coffee [15]. These apparent discrepancies highlight the inherent limitations of observational studies, in that causality cannot be inferred from associations alone. Lifestyle and socioe- conomic factors are important determinants of T2DM as well as coffee consumption, which may confound the association between T2DM and coffee use in many ways.

Definite proof for a causal relation between coffee consumption and T2DM risk should be obtained through large randomized controlled trials, of sufficient duration to detect effects on T2DM incidence. To my knowledge, no such studies have been published yet or have been registered at trial registries (http://www.who.int/ictrp/en/). Importantly, such trials should also deal with safety issues. Some authors have expressed concerns related to the consumption of coffee and cardiovascular disease [17,18]. Although recent observational studies suggest that these concerns may be unfounded [19-21], these issues will also need to be addressed.

\section{How could coffee consumption reduce the risk of T2DM?}

It is still not completely clear how coffee consumption might reduce the risk of T2DM. Paradoxically, placebo controlled studies in healthy volunteers observed that short-term caffeine administration reduced rather than improved insulin sensitivity [22]. Moreover, in a placebo controlled study in patients with T2DM, caffeine produced higher average daytime glucose concentrations and exaggerated post-prandial glucose responses [23]. Possibly, the effects of isolated caffeine administration on glucose metabolism under these laboratory conditions differ from those of longterm habitual caffeine intake as part of coffee consumption [24,25]. The association between coffee intake and reduced T2DM might also be due to coffee components other than caffeine. This would be in line with the observation from epidemiological studies that decaffeinated coffee also reduces T2DM risk [16]. Coffee beans contain thousands of constituents, including lipids, proteins, carbohydrates, vitamins, and minerals [24]. Alone, or through synergistic effects with caffeine, these compounds may affect T2DM risk through multiple mechanisms, including weight loss, thermogenesis, antioxidant effects, effects on the gut and the liver, and modulation of satiety [24,26]. A detailed discussion of these mechanisms is beyond the scope of this paper. The reader is referred to recent reviews [24-27]. 


\section{T2DM, COGNITION, AND DEMENTIA}

\section{Cognition in non-demented individuals with T2DM}

A large number of studies have addressed cognition in non-demented individuals with T2DM (reviewed in [28-30]). Studies on pre-diabetic stages of glucose dysmetabolism are somewhat scarcer [28,29], but there is an abundant number of studies on each of the individual vascular risk factors that constitute the metabolic syndrome, in particular hypertension (reviewed in [29]).

Cross-sectional studies in patients with T2DM report cognitive decrements, particularly on psychomotor efficiency, executive function, and learning and memory skills, relative to controls without DM (reviewed in [28, 31]). The magnitude of the decrements appears to vary with age, with effect sizes ranging from 0.4 to 1.0 standard deviation units $[28,31]$ in study populations with a mean age above 65 , and somewhat smaller effect sizes $(<0.5)$ in populations with a mean age below $60[28$, $31]$.

Over the past years our research group has applied the same standardized detailed psychometric evaluation in a number of cohorts of patients with T2DM $(\sim 400$ in total) [32-34]. Each cohort included non-diabetic controls, and possible confounding effects of age, sex, education, and pre-morbid IQ were carefully taken into account. Interestingly, cognitive decrements relative to the control groups were quite consistent across the studies, despite marked differences in diabetes duration of the patients involved. In individuals with screeningdetected T2DM of 2 years [34] or 5-10 years [32] duration effect sizes were $\sim 0.2$ and $\sim 0.3$, respectively. In individuals with 10 years duration of T2DM, diagnosed in regular care, effect sizes were $\sim 0.3$ [33]. Moreover, when we applied the same testing protocol to individuals with the metabolic syndrome without T2DM, effect sizes relative to controls were $\sim 0.3$ [32].

The overall picture that emerges from these crosssectional studies is that the decrements are present in early (pre)diabetic stages and show limited progression with increasing diabetes duration. Longitudinal studies largely support this view. In a recent longitudinal study, with 4 years follow-up, we observed no accelerated decline in a well controlled T2DM group relative to controls [35]. Other longitudinal studies, that generally used relatively brief cognitive assessment batteries, also reported no or limited (up to $50 \%$ on top of the rate of normal aging) accelerated cognitive decline in individuals with T2DM [36-38].
It is essential to note that the observation that patients with T2DM do not show marked cognitive decline relative to controls as the group level does not mean that the impact of T2DM on cognition is negligible. Patients with T2DM are clearly overrepresented among the subgroup of individuals who show accelerated cognitive decline [36,37]. Indeed, T2DM is a risk factor for cognitive disturbances, such as mild cognitive impairment (MCI) or cognitive impairment no dementia (CIND) [39-41], concepts that are considered to capture intermediate stages of cognitive dysfunction between normal cognitive aging and dementia. The challenge for the years to come is to identify the factors that predispose individual patients with T2DM to accelerated cognitive decline.

\section{T2DM and dementia}

In a systematic review of longitudinal populationbased studies we have shown that the incidence of dementia in patients with diabetes was increased by 50 to $100 \%$, relative to non-diabetic individuals [42]. Although this increased incidence was quite consistent across the studies included in our review, it should be noted that more recent studies did not find a significant relation between diabetes and dementia [43], or only observed significant relations in subgroups of patients, for example in patients with undiagnosed diabetes [44], or in those patients that did not have an apolipoprotein $\mathrm{E} \varepsilon 4$ allele [45]. The majority of available studies subdivided dementia cases in Alzheimer's disease (AD) or vascular dementia (VaD), based on clinical diagnostic criteria. Given the clear association between T2DM and stroke, it does not come as a surprise that diabetes is associated with $\mathrm{VaD}$ [42]. The majority of studies included in our systematic review also observed an association between T2DM and $\mathrm{AD}$, but it has to be acknowledged that clinical diagnostic criteria cannot reliably distinguish between typical AD type pathology and vascular lesions in the brain, even if the diagnostic work-up includes brain imaging.

For dementia in general, outside of the context of diabetes, it is increasingly acknowledged that among the oldest individuals the majority of demented patients show mixed dementia at autopsy, also in people clinically diagnosed with AD [46,47]. Moreover, despite the fact that $\mathrm{AD}$ is the most common type of dementia that is diagnosed at old age, in the oldest old, AD type pathology at autopsy distinguishes poorly between those individuals who were demented in life and those who were not [48]. When it comes to 
diabetes, an increasing number of autopsy studies on possible pathological dementia correlates is becoming available. Thus far the picture that emerges from these studies is that diabetes is not associated with AD-type pathology, whereas vascular pathology in the brain is more common [49-52].

\section{Brain imaging in $T 2 D M$}

Brain imaging studies in T2DM predominantly involve individuals without frank cognitive impairments (reviewed in [53]). Cross-sectional studies consistently report modest degrees of global atrophy relative to controls (reviewed in [53,54]). Reduced hippocampal and/or amygdalar volumes have also been reported [55-57], but it is not yet clear whether atrophy of these temporal lobe structures is out of proportion to the global cerebral atrophy. With regard to vascular lesions, T2DM is associated with a 1.5 to 2 fold increase in the prevalence and incidence of infarcts (reviewed in [53]). The relationship between T2DM and white matter hyperintensities (WMHs) is less evident. Several large population-based studies did not observe a significant association between T2DM and WMHs (reviewed in [53]). However, case-control studies that applied more refined WMH rating scales or volumetric measurements did observe a modest increase in WMH severity in patients with T2DM [54,58]. A recent study also identified T2DM is a risk factor for $\mathrm{WMH}$ progression [59].

\section{Underlying mechanisms}

There are many mechanisms through which T2DM may affect the brain, including vascular disturbances, glucose toxicity, hypoglycemic episodes and disturbances of cerebral insulin signalling (reviewed in [6062]). Other factors, such as glucocorticoids, may modulate these effects $[63,64]$. The next section of this review provides a summary of these mechanisms.

"Glucose-toxicity" is generally assumed to be one of the key factors in the development of long-term diabetic complications [65], particularly in so-called microvascular diabetic complications such as retinopathy, nephropathy and neuropathy. Toxic effects of high glucose levels are mediated through an enhanced flux of glucose through the so-called polyol and hexosamine pathways, disturbances of intracellular second messenger pathways, an imbalance in the generation and scavenging of reactive oxygen species, and by advanced glycation of important functional and struc- tural proteins [65]. Such "toxic" effects of hyperglycaemia may also lead to slowly progressive functional and structural abnormalities in the brain, either through direct effects of elevated glucose levels on brain tissue or through abnormalities in the cerebral microvasculature [66]. Chronically hyperglycaemic rodents indeed express cognitive impairments and abnormalities in synaptic plasticity [67]. In the context of this review it is of particular interest that these abnormalities in plasticity may involve alterations in adenosine receptor density [68,69]. Possibly, caffeine, as a non-selective adenosine receptor antagonist [70], might modify these processes.

Vascular disturbances are also an obvious factor to consider. T2DM and associated vascular risk factors clearly increase the risk of ischemic stroke [71,72]. Chronic exposure to hyperglycaemia may also lead to abnormalities in cerebral capillaries, such as basement membrane thickening [73,74]. Cerebral blood flow is reduced in experimental models of diabetes [75], but the effects of T2DM on cerebral perfusion in humans are less clear [76].

Disturbances in cerebral insulin signaling are another intriguing lead $[77,78]$. While the brain has long been considered an insulin insensitive organ, it is now known that insulin has many physiological effects on the brain $[79,80]$. Insulin is transported actively across the blood-brain barrier [81] and may even be produced locally in the brain [82]. Insulin receptors are distributed throughout the brain, with particular abundance in, for example, the hippocampus and the cortex [83]. Insulin modulates food-intake and energy homeostasis [84] and may also be involved in learning and memory [85]. Ageing affects insulin and its receptor in the brain, and these changes may be even more pronounced in patients with $\mathrm{AD}[82,86,87]$. The observation that activation of the insulin receptor was impaired in brain autopsy samples of patients with $\mathrm{AD}$ has given rise to the hypothesis that AD may be qualified as "an insulin resistant brain state" [86]. Finally, alterations in insulin and glucose homeostasis may also affect amyloid$\beta$ and tau metabolism [78,88]. It is tempting to suggest that hyperinsulinaemia and insulin resistance in patients with T2DM may thus disturb cerebral function and interfere with amyloid- $\beta$ metabolism, thus mediating the increased dementia risk. Studies in animal models support this view $[89,90]$. It should be noted, however, that it is yet unknown how T2DM and its treatment affect insulin signaling in the brain in humans. Moreover, as indicated in a previous section of this review, autopsy studies in humans do not observe increased AD pathology in patients with T2DM. 
In summary, many of the processes that have been implicated in the pathogenesis of brain ageing and dementia, including (micro)vascular disease, cerebral glucose dysmetabolism, oxidative stress, and aberrant insulin signaling can be aggravated by T2DM. It has to be acknowledged, however, that it is still unclear which of these processes primarily determine the increased dementia risk in T2DM. In fact, the prime determinants of cognitive decline may even differ between patients, depending on their level of glycemic control, vascular risk factor profile, co-morbid conditions and individual (genetic) susceptibility.

\section{CAFFEINE, COGNITION, AND DEMENTIA}

The potential impact of caffeine on cognition and the relation between caffeine intake and dementia will be addressed in other reviews in this theme issue of the Journal of Alzheimer's disease. In short, caffeine can affect the brain through adenosine receptors, influencing several aspects of cerebral function, including cognition [70,91]. Studies in animal models provide evidence of neuroprotective effects and modulation of the metabolism of amyloid- $\beta$ [91]. As such the relation between caffeine consumption and $\mathrm{AD}$ is of considerable interest. Indeed, evidence is emerging that caffeine consumption is associated with decelerated cognitive decline [92]. In addition, midlife coffee consumption was associated with a decreased late life dementia risk [93]. On the other hand, caffeine intake in older individuals did not modulate the risk of incident dementia over 4 years follow-up [92]. Again it should be emphasized that no causal relationships can be inferred from these observational studies, and this topic will need further investigation.

\section{CAFFEINE, DIABETES, AND COGNITION: FIVE CUPS A DAY KEEPS DEMENTIA AWAY?}

A compound that reduces the risk of T2DM and at the same time protects the brain against the effects of cognitive aging or dementia would be the ultimate solution for cognitive decline and dementia in the context of T2DM. It will be evident from this review that we are currently unable to establish beyond doubt if caffeine is such a compound. Thus far, no studies have specifically targeted potential effects of caffeine or coffee on cognition in patients with T2DM, but studies in experimentally diabetic rodents do suggest that caffeine may attenuate some of the effects of diabetes on the brain [94]. Mechanistic studies show a range of potential targets through which coffee/caffeine could exert these beneficial effects. However, further, dedicated studies are required.

In conclusion, coffee/caffeine consumption is associated with a decreased risk of T2DM and possibly also with a decreased dementia risk. At present we cannot be certain that these associations are causal. There have been concerns of the cardiovascular safety of high coffee consumption, although these concerns are not supported by recent large epidemiological surveys. For now, recommendations for coffee consumption in individuals with T2DM or pre-diabetic stages are difficult to establish, but it should be acknowledged that caffeine does appear to have several properties that warrant further investigations in this field.

\section{DISCLOSURE STATEMENT}

The author's disclosure is available online (http:// www.j-alz.com/disclosures/view.php?id=240).

\section{REFERENCES}

[1] Biessels GJ, Deary IJ, Ryan CM (2008) Cognition and diabetes: a lifespan perspective. Lancet Neurol 7, 184-190.

[2] Stumvoll M, Goldstein BJ, van Haeften TW (2005) Type 2 diabetes: principles of pathogenesis and therapy. Lancet $\mathbf{3 6 5}$, 1333-1346.

[3] American Diabetes Association (2005) Diagnosis and classification of diabetes mellitus. Diabetes Care 28, S37-S42.

[4] Eckel RH, Grundy SM, Zimmet PZ (2005) The metabolic syndrome. Lancet 365, 1415-1428.

[5] Reaven GM (1988) Banting lecture 1988. Role of insulin resistance in human disease. Diabetes 37, 1595-1607.

[6] Beckman JA, Creager MA, Libby P (2002) Diabetes and atherosclerosis: epidemiology, pathophysiology, and management. JAMA 287, 2570-2581.

[7] Donnelly R, Emslie-Smith AM, Gardner ID, Morris AD (2000) ABC of arterial and venous disease: vascular complications of diabetes. BMJ 320, 1062-1066.

[8] Bruno G, Runzo C, Cavallo-Perin P, Merletti F, Rivetti M, Pinach S, Novelli G, Trovati M, Cerutti F, Pagano G (2005) Incidence of type 1 and type 2 diabetes in adults aged 30-49 years: the population-based registry in the province of Turin, Italy. Diabetes Care 28, 2613-2619.

[9] Berger B, Stenstrom G, Sundkvist G (1999) Incidence, prevalence, and mortality of diabetes in a large population. A report from the Skaraborg Diabetes Registry. Diabetes Care 22, 773-778.

[10] Liese AD, D'Agostino RB, Jr., Hamman RF, Kilgo PD, Lawrence JM, Liu LL, Loots B, Linder B, Marcovina S, Rodriguez B, Standiford D, Williams DE (2006) The burden of diabetes mellitus among US youth: prevalence estimates from the SEARCH for Diabetes in Youth Study. Pediatrics 118, 1510-1518. 
[11] Wild S, Roglic G, Green A, Sicree R, King H (2004) Global prevalence of diabetes: estimates for the year 2000 and projections for 2030. Diabetes Care 27, 1047-1053.

[12] Mainous AG, III, Baker R, Koopman RJ, Saxena S, Diaz VA, Everett CJ, Majeed A (2007) Impact of the population at risk of diabetes on projections of diabetes burden in the United States: an epidemic on the way. Diabetologia 50, 934-940.

[13] Zimmet P, Alberti KG, Shaw J (2001) Global and societal implications of the diabetes epidemic. Nature 414, 782-787.

[14] van Dam RM, Feskens EJ (2002) Coffee consumption and risk of type 2 diabetes mellitus. Lancet 360, 1477-1478.

[15] van Dam RM, Hu FB (2005) Coffee consumption and risk of type 2 diabetes: a systematic review. JAMA 294, 97-104.

[16] Pereira MA, Parker ED, Folsom AR (2006) Coffee consumption and risk of type 2 diabetes mellitus: an 11-year prospective study of 28812 postmenopausal women. Arch Intern Med 166, 1311-1316.

[17] Campos H, Baylin A (2007) Coffee consumption and risk of type 2 diabetes and heart disease. Nutr Rev 65, 173-179.

[18] Riksen NP, Rongen GA, Smits P (2009) Acute and long-term cardiovascular effects of coffee: implications for coronary heart disease. Pharmacol Ther 121, 185-191.

[19] Zhang W, Lopez-Garcia E, Li TY, Hu FB, van Dam RM (2009) Coffee consumption and risk of cardiovascular diseases and all-cause mortality among men with type 2 diabetes. Diabetes Care 32, 1043-1045.

[20] Lopez-Garcia E, Rodriguez-Artalejo F, Rexrode KM, Logroscino G, Hu FB, van Dam RM (2009) Coffee consumption and risk of stroke in women. Circulation 119, 1116-1123.

[21] van Dam RM (2008) Coffee consumption and risk of type 2 diabetes, cardiovascular diseases, and cancer. Appl Physiol Nutr Metab 33, 1269-1283.

[22] MacKenzie T, Comi R, Sluss P, Keisari R, Manwar S, Kim J, Larson R, Baron JA (2007) Metabolic and hormonal effects of caffeine: randomized, double-blind, placebo-controlled crossover trial. Metabolism 56, 1694-1698.

[23] Lane JD, Feinglos MN, Surwit RS (2008) Caffeine increases ambulatory glucose and postprandial responses in coffee drinkers with type 2 diabetes. Diabetes Care 31, 221-222.

[24] Tunnicliffe JM, Shearer J (2008) Coffee, glucose homeostasis, and insulin resistance: physiological mechanisms and mediators. Appl Physiol Nutr Metab 33, 1290-1300.

[25] Acheson KJ (2005) Caffeine and insulin sensitivity. Metab Syndr Relat Disord 3, 19-25.

[26] Greenberg JA, Boozer CN, Geliebter A (2006) Coffee, diabetes, and weight control. Am J Clin Nutr 84, 682-693.

[27] Diepvens K, Westerterp KR, Westerterp-Plantenga MS (2007) Obesity and thermogenesis related to the consumption of caffeine, ephedrine, capsaicin, and green tea. Am J Physiol 292 , R77-R85.

[28] Awad N, Gagnon M, Messier C (2004) The relationship between impaired glucose tolerance, type 2 diabetes, and cognitive function. J Clin Exp Neuropsychol 26, 1044-1080.

[29] van den Berg E, Kloppenborg RP, Kessels RP, Kappelle LJ, Biessels GJ (2009) Type 2 diabetes mellitus, hypertension, dyslipidemia and obesity: A systematic comparison of their impact on cognition. Biochim Biophys Acta 1792, 470-481.

[30] Allen KV, Frier BM, Strachan MWJ (2004) The relationship between type 2 diabetes and cognitive dysfunction: longitudinal studies and their methodological limitations. Eur J Pharmacol 490, 169-175.

[31] Stewart R, Liolitsa D (1999) Type 2 diabetes mellitus, cognitive impairment and dementia. Diabet Med 16, 93-112.
[32] van den Berg E, Dekker JM, Nijpels G, Kessels RP, Kappelle LJ, De Haan EH, Heine RJ, Stehouwer CD, Biessels GJ (2008) Cognitive functioning in elderly persons with type 2 diabetes and metabolic syndrome: the Hoorn study. Dement Geriatr Cogn Disord 26, 261-269.

[33] Brands AMA, van den Berg E, Manschot SM, Biessels GJ, Kappelle LJ, De Haan EH, Kessels RP (2007) A detailed profile of cognitive dysfunction and its relation to psychological distress in patients with type 2 diabetes mellitus. J Int $\mathrm{Neu}$ ropsychol Soc 13, 288-297.

[34] Ruis C, Biessels GJ, Gorter KJ, van den DM, Kappelle LJ, Rutten GE (2009) Cognition in the early stage of type 2 Diabetes Mellitus. Diabetes Care 32, 1261-1265.

[35] van den Berg E, Reijmer YD, de Bresser J, Kessels RP, Kappelle LJ, Biessels GJ (2010) A 4 year follow-up study of cognitive functioning in patients with type 2 diabetes mellitus. Diabetologia 53, 58-65.

[36] Gregg EW, Yaffe K, Cauley JA, Rolka DB, Blackwell TL, Narayan KM, Cummings SR (2000) Is diabetes associated with cognitive impairment and cognitive decline among older women? Study of Osteoporotic Fractures Research Group. Arch Intern Med 160, 174-180.

[37] Kanaya AM, Barrett-Connor E, Gildengorin G, Yaffe K (2004) Change in cognitive function by glucose tolerance status in older adults: a 4-year prospective study of the Rancho Bernardo study cohort. Arch Intern Med 164, 1327-1333.

[38] van den Berg E, de Craen AJ, Biessels GJ, Gussekloo J, Westendorp RG (2006) The impact of diabetes mellitus on cognitive decline in the oldest of the old: a prospective population-based study. Diabetologia 49, 2015-2023.

[39] van den Berg E, Kessels RP, De Haan EH, Kappelle LJ, Biessels GJ (2005) Mild impairments in cognition in patients with type 2 diabetes mellitus: the use of the concepts MCI and CIND. J Neurol Neurosurg Psychiatry 76, 1466-1467.

[40] Yaffe K, Blackwell T, Kanaya AM, Davidowitz N, BarrettConnor E, Krueger K (2004) Diabetes, impaired fasting glucose, and development of cognitive impairment in older women. Neurology 63, 658-663.

[41] Luchsinger JA, Reitz C, Patel B, Tang MX, Manly JJ, Mayeux $\mathrm{R}$ (2007) Relation of diabetes to mild cognitive impairment. Arch Neurol 64, 570-575.

[42] Biessels GJ, Staekenborg S, Brunner E, Brayne C, Scheltens $\mathrm{P}$ (2006) Risk of dementia in diabetes mellitus: a systematic review. Lancet Neurol 5, 64-74.

[43] Fernandez Martinez M, Castro Flores J, Perez de Las Heras S, Mandaluniz Lekumberri A, Gordejuela Menocal M, Zarranz Imirizaldu JJ (2008) Risk factors for dementia in the epidemiological study of Munguialde County (Basque Country-Spain). BMC Neurol 8, 39.

[44] Xu WL, von SE, Qiu CX, Winblad B, Fratiglioni L (2009) Uncontrolled diabetes increases the risk of Alzheimer's disease: a population-based cohort study. Diabetologia 52, 1031-1039.

[45] Akomolafe A, Beiser A, Meigs JB, Au R, Green RC, Farrer LA, Wolf PA, Seshadri S (2006) Diabetes mellitus and risk of developing Alzheimer disease: results from the Framingham Study. Arch Neurol 63, 1551-1555.

[46] Gold G, Giannakopoulos P, Herrmann FR, Bouras C, Kovari E (2007) Identification of Alzheimer and vascular lesion thresholds for mixed dementia. Brain 130, 2830-2836.

[47] Schneider JA, Arvanitakis Z, Bang W, Bennett DA (2007) Mixed brain pathologies account for most dementia cases in community-dwelling older persons. Neurology 69, 2197-2204. 
[48] Savva GM, Wharton SB, Ince PG, Forster G, Matthews FE, Brayne C (2009) Age, neuropathology, and dementia. $N$ Engl J Med 360, 2302-2309.

[49] Schnaider Beeri M., Silverman JM, Davis KL, Marin D, Grossman HZ, Schmeidler J, Purohit DP, Perl DP, Davidson M, Mohs RC, Haroutunian V (2005) Type 2 diabetes is negatively associated with Alzheimer's disease neuropathology. $J$ Gerontol A Biol Sci Med Sci 60, 471-475.

[50] Arvanitakis Z, Schneider JA, Wilson RS, Li Y, Arnold SE, Wang Z, Bennett DA (2006) Diabetes is related to cerebral infarction but not to AD pathology in older persons. Neurology 67, 1960-1965.

[51] Alafuzoff I, Aho L, Helisalmi S, Mannermaa A, Soininen $\mathrm{H}$ (2008) beta-Amyloid deposition in brains of subjects with diabetes. Neuropathol Appl Neurobiol 35, 60-68.

[52] Nelson PT, Smith CD, Abner EA, Schmitt FA, Scheff SW, Davis GJ, Keller JN, Jicha GA, Davis D, Wang-Xia W, Hartman A, Katz DG, Markesbery WR (2008) Human cerebral neuropathology of Type 2 diabetes mellitus. Biochim Biophys Acta 1792, 454-469.

[53] van Harten B, de Leeuw FE, Weinstein HC, Scheltens P, Biessels GJ (2006) Brain Imaging in Patients With Diabetes: A systematic review. Diabetes Care 29, 2539-2548.

[54] Jongen C, Biessels GJ (2008) Structural brain imaging in diabetes: a methodological perspective. Eur J Pharmacol 585, 208-218.

[55] den Heijer T, Vermeer SE, van Dijk EJ, Prins ND, Koudstaal PJ, Hofman A, Breteler MM (2003) Type 2 diabetes and atrophy of medial temporal lobe structures on brain MRI. Diabetologia 46, 1604-1610.

[56] Korf ES, van Straaten EC, de Leeuw FE, van der Flier WM, Barkhof F, Pantoni L, Basile AM, Inzitari D, Erkinjuntti T, Wahlund LO, Rostrup E, Schmidt R, Fazekas F, Scheltens P (2007) Diabetes mellitus, hypertension and medial temporal lobe atrophy: the LADIS study. Diabet Med 24, 166-171.

[57] Korf ES, White LR, Scheltens P, Launer LJ (2006) Brain aging in very old men with type 2 diabetes: the Honolulu-Asia Aging Study. Diabetes Care 29, 2268-2274.

[58] van Harten B, Oosterman JM, Potter van Loon BJ, Scheltens P, Weinstein HC (2007) Brain lesions on MRI in elderly patients with type 2 diabetes mellitus. Eur Neurol 57, 70-74.

[59] Gouw AA, van der Flier WM, Fazekas F, van Straaten EC, Pantoni L, Poggesi A, Inzitari D, Erkinjuntti T, Wahlund LO, Waldemar G, Schmidt R, Scheltens P, Barkhof F (2008) Progression of white matter hyperintensities and incidence of new lacunes over a 3-year period: the Leukoaraiosis and Disability study. Stroke 39, 1414-1420.

[60] Gispen WH, Biessels GJ (2000) Cognition and synaptic plasticity in diabetes mellitus. Trends Neurosci $\mathbf{2 3}, 542-549$.

[61] Li L, Holscher C (2007) Common pathological processes in Alzheimer disease and type 2 diabetes: a review. Brain Res Rev 56, 384-402.

[62] Sima AAF, Kamiya H, Li ZG (2004) Insulin, C-peptide, hyperglycemia, and central nervous system complications in diabetes. Eur J Pharmacol 490, 187-197.

[63] Stranahan AM, Arumugam TV, Cutler RG, Lee K, Egan JM, Mattson MP (2008) Diabetes impairs hippocampal function through glucocorticoid-mediated effects on new and mature neurons. Nature Neurosci 11, 309-317.

[64] Reagan LP, Grillo CA, Piroli GG (2008) The As and Ds of stress: metabolic, morphological and behavioral consequences. Eur J Pharmacol 585, 64-75.

[65] Brownlee M (2001) Biochemistry and molecular cell biology of diabetic complications. Nature 414, 813-820.
[66] Biessels GJ, Van der Heide LP, Kamal A, Bleys RL, Gispen WH (2002) Ageing and diabetes: implications for brain function. Eur J Pharmacol 441, 1-14.

[67] Biessels GJ, Kamal A, Ramakers GM, Urban IJ, Spruijt BM, Erkelens DW, Gispen WH (1996) Place learning and hippocampal synaptic plasticity in streptozotocin-induced diabetic rats. Diabetes 45, 1259-1266.

[68] Morrison PD, Mackinnon MW, Bartrup JT, Skett PG, Stone TW (1992) Changes in adenosine sensitivity in the hippocampus of rats with streptozotocin-induced diabetes. Br J Pharmacol 105, 1004-1008.

[69] Duarte JM, Oliveira CR, Ambrósio AF, Cunha RA (2006) Modification of adenosine A1 and A2A receptor density in the hippocampus of streptozotocin-induced diabetic rats. Neurochem Int 48, 144-150.

[70] Ribeiro JA, Sebastião AM, de Mendonça A (2002) Adenosine receptors in the nervous system: pathophysiological implications. Prog Neurobiol 68, 377-392.

[71] Mankovsky BN, Ziegler D (2004) Stroke in patients with diabetes mellitus. Diabetes Metab Res Rev 20, 268-287.

[72] Almdal T, Scharling H, Jensen JS, Vestergaard H (2004) The independent effect of type 2 diabetes mellitus on ischemic heart disease, stroke, and death: a population-based study of 13,000 men and women with 20 years of follow-up. Arch Intern Med 164, 1422-1426.

[73] Johnson PC, Brenedel K, Meezan E (1982) Thickened cerebral cortical capillary basement membranes in diabetics. Arch Pathol Lab Med 106, 214-217.

[74] McCuskey PA, McCuskey RS (1984) In vivo and electron microscopic study of the development of cerebral diabetic microangiography. Microcirc Endothelium Lymphatics 1, 221244.

[75] Manschot SM, Biessels GJ, Cameron NE, Cotter MA, Kamal A, Kappelle LJ, Gispen WH (2003) Angiotensin converting enzyme inhibition partially prevents deficits in water maze performance, hippocampal synaptic plasticity and cerebral blood flow in streptozotocin-diabetic rats. Brain Res 966, 274-282.

[76] Tiehuis AM, Vincken KL, van den Berg E, Hendrikse J, Manschot SM, Mali WP, Kappelle LJ, Biessels GJ (2008) Cerebral perfusion in relation to cognitive function and type 2 diabetes. Diabetologia 51, 1321-1326.

[77] Craft S (2009) The role of metabolic disorders in Alzheimer disease and vascular dementia: two roads converged. Arch Neurol 66, 300-305.

[78] Craft S (2007) Insulin resistance and Alzheimer's disease pathogenesis: potential mechanisms and implications for treatment. Curr Alzheimer Res 4, 147-152.

[79] Hallschmid M, Schultes B (2009) Central nervous insulin resistance: a promising target in the treatment of metabolic and cognitive disorders? Diabetologia 52, 2264-2269.

[80] Holscher C, Li L (2010) New roles for insulin-like hormones in neuronal signalling and protection: New hopes for novel treatments of Alzheimer's disease? Neurobiol Aging, in press.

[81] Banks WA (2004) The source of cerebral insulin. Eur J Pharmacol 490, 5-12.

[82] Steen E, Terry BM, Rivera EJ, Cannon JL, Neely TR, Tavares R, Xu XJ, Wands JR, de la Monte SM (2005) Impaired insulin and insulin-like growth factor expression and signaling mechanisms in Alzheimer's disease-is this type 3 diabetes? $J$ Alzheimers Dis 7, 63-80.

[83] Bondy CA, Cheng CM (2004) Signaling by insulin-like growth factor 1 in brain. Eur J Pharmacol 490, 25-31.

[84] Gerozissis K (2004) Brain insulin and feeding: a bi-directional communication. Eur J Pharmacol 490, 59-70. 
[85] Zhao W, Alkon DL (2001) Role of insulin and insulin receptor in learning and memory. Mol Cell Endocrinol 177, 125-134.

[86] Frolich L, Blum-Degen D, Bernstein HG, Engelsberger S, Humrich J, Laufer S, Muschner D, Thalheimer A, Turk A, Hoyer S, Zochling R, Boissl KW, Jellinger K, Riederer P (1998) Brain insulin and insulin receptors in aging and sporadic Alzheimer's disease. J Neural Transm 105, 423-438.

[87] Caccamo A, Oddo S, Sugarman MC, Akbari Y, LaFerla FM (2005) Age- and region-dependent alterations in Abetadegrading enzymes: implications for Abeta-induced disorders. Neurobiol Aging 26, 645-654.

[88] Gasparini L, Xu H (2003) Potential roles of insulin and IGF-1 in Alzheimer's disease. Trends Neurosci 26, 404-406.

[89] Li ZG, Zhang W, Sima AA (2007) Alzheimer-like changes in rat models of spontaneous diabetes. Diabetes 56, 1817-1824.

[90] Jolivalt CG, Lee CA, Beiswenger KK, Smith JL, Orlov M, Torrance MA, Masliah E (2008) Defective insulin signaling pathway and increased glycogen synthase kinase-3 activity in the brain of diabetic mice: parallels with Alzheimer's disease and correction by insulin. J Neurosci Res 86, 3265-3274.

91] Rosso A, Mossey J, Lippa CF (2008) Caffeine: neuroprotective functions in cognition and Alzheimer's disease. Am J Alzheimers Dis Other Demen 23, 417-422.

[92] Ritchie K, Carriere I, de MA, Portet F, Dartigues JF, Rouaud O, Barberger-Gateau P, Ancelin ML (2007) The neuroprotective effects of caffeine: a prospective population study (the Three City Study). Neurology 69, 536-545.

[93] Eskelinen MH, Ngandu T, Tuomilehto J, Soininen H, Kivipelto M (2009) Midlife coffee and tea drinking and the risk of latelife dementia: a population-based CAIDE study. J Alzheimers Dis 16, 85-91.

[94] Duarte JM, Carvalho RA, Cunha RA, Gruetter R (2009) Caffeine consumption attenuates neurochemical modifications in the hippocampus of streptozotocin-induced diabetic rats. $J$ Neurochem 111, 368-379. 